\title{
Refusal of Food Ingestion of Old Male BUF/Mna Rats in Metabolic Cages
}

\author{
Mutsushi Matsuyama ${ }^{1, *}$, Kazuo Kato ${ }^{2}$ \\ ${ }^{1}$ Department of Cell Biology and Anatomy, Fujita Health University School of Medicine, 1-98 Dengakugakubo, Kutsukake-cho, \\ Toyoake-shi, Aichi-ken Japan \\ ${ }^{2}$ Department of Pathology, Chubu Rousai Hospital, 1-10-6 Komei, Minato-ku, Nagoya-shi, Aichi-ken 455-8530, Japan \\ *Corresponding author: mmatsuya@fujita-hu.ac.jp
}

Received October 23, 2014; Revised February 02, 2015; Accepted February 11, 2015

Abstract Forty-four percent of old male BUF/Mna rats showed refusal of food intake when they were isolated in metabolic cages.

Keywords: refusal of food ingestion, old male BUF/Mna rats, metabolic cage

Cite This Article: Mutsushi Matsuyama, and Kazuo Kato, "Refusal of Food Ingestion of Old Male BUF/Mna Rats in Metabolic Cages." Research in Psychology and Behavioral Sciences, vol. 3, no. 1 (2015): 5-6. doi: 10.12691/rpbs-3-1-2.

\section{Introduction}

Rats of the BUF/Mna (BUF) strain develop thymus hyperplasia, thymoma, muscle atrophy, and proteinuria in almost $100 \%$ [1-10]. During the course of the experiment on proteinuria, we incidentally found that some of old male rats of this strain refused to take food in isolated metabolic cages.

\section{Materials and Methods}

Nineteen to 46 weeks old rats of the BUF, ACI/NMs (ACI), and WKY/NCrj (WKY) strains were singly placed in metabolic cages, made of plastics and wire net, for 24 hrs from AM. 8 to AM. 8 of the next day (Figure 1). Volume of urine, and intakes of pellet diet and water were measured. Content of urinary protein was measured by the method described in the previous paper [1]. Pellet diet (CMF, Oriental Yeast, Tokyo, Japan) and tap water were given freely, and actual intakes of food were measured, respectively.

\section{Results}

Eight of 18 male BUF rats (44\%) refused to take pellet diet (Table 1), feeding 0 gr. Female BUF rats, female and male ACI and WKY rats fed 4-20 gr during the 24 hrs, except 1 rat each (Figure 1). Older and heavier BUF rats tended to refuse the intake of the diet during the dwelling in the metabolic cages (Table 1). Refused rats drank smaller amount of water (data were not shown).

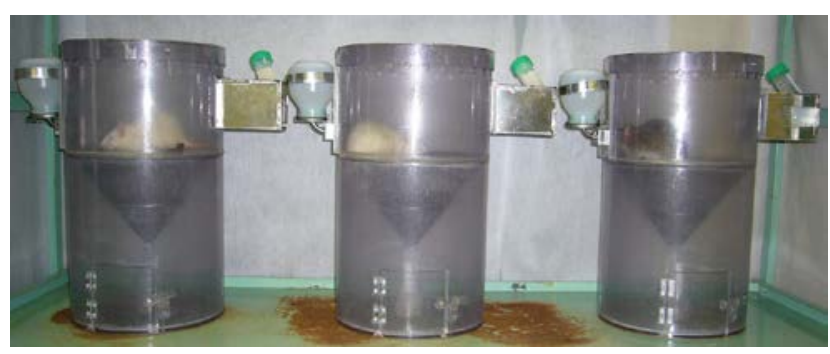

Figure 1.

Table 1. Results of 24 hours collection of urine of rats of the BUF

\begin{tabular}{|c|c|c|c|c|c|c|c|}
\hline \multirow{2}{*}{ Strain } & \multirow{2}{*}{ Sex } & \multirow{2}{*}{ Age\# } & \multirow{2}{*}{\multicolumn{2}{|c|}{$\begin{array}{l}\text { No. \& \% of } \\
\text { refused rats }\end{array}$}} & \multirow{2}{*}{ Av. Intake of food (g) } & \multicolumn{2}{|c|}{ Average body weight (g) } \\
\hline & & & & & & Refused & Not refused \\
\hline BUF & $\mathrm{F}$ & 35 & $0 / 10$ & 0 & $11.0 \pm 3.1$ & $(-)$ & $248 \pm 37$ \\
\hline ACI & $\mathrm{F}$ & 27 & $0 / 12$ & 0 & $6.3 \pm 3.8$ & $(-)$ & $198 \pm 33$ \\
\hline WKY & $\mathrm{F}$ & 21 & $1 / 17$ & 6 & $14.5 \pm 4.2^{*}$ & 192 & $233 \pm 27$ \\
\hline BUF & $\mathrm{M}$ & 43 & $8 / 18$ & 44 & $9.3 \pm 3.3^{*}$ & $472 \pm 83$ & $361 \pm 86$ \\
\hline ACI & $\mathrm{M}$ & 19 & $1 / 18$ & 6 & $9.3 \pm 3.5^{*}$ & 278 & $269 \pm 60$ \\
\hline WKY & $\mathrm{M}$ & 22 & $0 / 9$ & 0 & $12.6 \pm 3.5$ & $(-)$ & $292 \pm 64$ \\
\hline
\end{tabular}

\# Weeks.

F: female, M: male.

*Average values of the food intake in the rats, excluded those of the refused.

\section{Discussion}

Mechanism of the occurrence of acute anorexia in male BUF rats is not known. However, the BUF strain is known as susceptible strain for the development of thymus 
hyperplasia, thymoma, muscle atrophy, and proteinuria (Matsuyama, 1990). It is known that proteinuria of BUF rats depend on the mutation of actin related protein 3 [ARP3]. Therefore, it can be assumed that NPY/AgRP neuron, which regulates appetite [3,13], might be impaired by the dysfunction of ARP3. These diseases develop almost all rats of both sexes in the strain. However, the refusal of food intake occurred exclusively in males. Male $\mathrm{BUF} / \mathrm{Mna}$ rats may be more nervous for the change of the dwelling.

\section{References}

[1] Akiyama K., Morita H., Suetsugu S. et al. Actin-related protein 3 (Arp3) is mutated in proteinuric BUF/Mna rats. Mamm. Genome 2008; 19, 41-50.

[2] Amo H., Saito M., Nagao S. et al. Genetic regulation of slowly progressing mild muscle atrophy in fast-twitch muscles of BUF/Mna rats. Muscle Nerve 1997; 20, 1258-1263.

[3] Graham M., Shutter J.R., Sarmiento U., et al. Over expression of Agrt leads to obesity in transgenic mice. Nat. Genet. 1997; 17: 273-274.

[4] Matsuyama M. Thymoma, Lymphocytic, Rat. In: Hemopoietic System. 1990; pp. 275-280 (eds T.C. Jones, J.M. Ward, U. Mohr, R.D. Hunt), Berlin: Springer-Verlag.

[5] Matsuyama M, Amo H. Host origin of lymphoid cells in thymomas developed from subcutaneous thymus grafts in Buffalo rats. Gann 1977; 293-300.
[6] Matsuyama M. \& Nagayo T. Development of thymoma and myasthenia in Buffalo/Mna rats. Proc. Jpn. Cancer Assoc. 36th Ann Meet. 1977; 36, 30.

[7] Matsuyama M., Yamada C., Hiai H. A single dominant susceptible gene determines spontaneous development of thymoma in BUF/Mna rat. Jpn. J. Cancer Res. (Gann) 1986; 77; 1066-1068.

[8] Matsuyama M., Matsuyama T., Ogiu T. et al. Nodular development of spontaneous epithelial thymoma in (ACI/NMs $\times$ BUF/Mna)F1 rats. Jpn. J. Cancer Res. Cancer Res (Gann) 1988; 79, 1031-1038.

[9] Matsuyama M., Kojima A., Katoh H. et al. (1989) Establishment of a congenic nude strain of rats, BUF/Mna-rnu. Suppression of thymomagenesis in heterozygous rats. In: Immune-deficient Animals in Experimental Medicine. eds B-q. Wu \& J. Zheng. Basel Karger pp 27-31.

[10] Murakumo Y., Takahashi M., Sharma N. et al. Mapping of two genetic loci, Ten-1 and Ten-2, associated with thymus enlargement in BUF/Mna rats. Mamm. Genome 1996, 7, 505-508.

[11] Murayama S., Yagyu S., Higo K. et al. A genetic locus susceptible to the overt proteinuria in BUF/Mna rat. Mamm. Genome 1998; 9: 886-8.

[12] Oyabu A., Higo K., Ye C. et al. (1999) Genetic mapping of the thymoma susceptible locus, Tsr1, in BUF/Mna rats. J Natl Cancer Cancer Inst 91 279-82.

[13] Shutter J. R., Graham M., Kinsey A. C. et al. Hypothalamic expression of ART, a novel gene related to agouti, is up-regulated in obese and diabetic mutant mice. Genes Dev. 1997. 11 593-602.

[14] Taguchi O., Kontani K., Ikeda H. et al. (1992) An intrinsic thymic epithelial abnormality is responsible for the spontaneous development of predominantly lymphocytic thymomas in BUF/Mna rats. Jpn. J. Cancer Res 1992; 83: 1161-71. 